\title{
WORK-FAMILY CONFLICT AMONG TURKISH MANAGERS: POTENTIAL ANTECEDENTS AND CONSEQUENCES ${ }^{1}$
}

\author{
MUSTAFA KOYUNCU \\ Doç.Dr.Nevşehir University \\ RONALD J. BURKE \\ Prof.Dr.,York University \\ LISA FIKSENBAUM \\ York University
}

\begin{abstract}
Although the work-family interface has received considerable research attention over the past two decades, $m$ inconsistent findings have been reported. One reason for this is the use of different work-family measures. Carlson, Kacmar and Williams (2000) developed and provided an initial validation of a new comprehensive measure of bi-directional work-family conflict having three forms: time-, strain- and behavior-based conflict. This study replicated and extended their work by employing a large sample of managers and professionals working in the manufacturing sector in Turkey and including additional antecedents and consequences. Data were collected from 877 respondents using anonymously completed questionnaires, a 58\%
\end{abstract}

\footnotetext{
${ }^{1}$ Preparation of this manuscript and conduct of the research was supported in part by York University and Nevsehir University. Ufuk Durna, Halil Demirer, Mehmet Tekinkus, Cetin Bektas and Fusun Tekin Acar assisted with data collection. We thank our respondents for their participation.
} 
response rate. The three measures of work-family conflict were highly reliable and inter-correlated to the same extent as reported by Carlson and her colleagues. The mean values in the Turkish sample on each were higher than those obtained I the US study, and the gender differences reported by Carlson and her colleagues were not present in the Turkish sample. Both job demands and work-oriented personality factors (NAch, feeling driven to work) were related to levels of work-family conflict. Strain-based conflict emerged as a stronger and more consistent predictor of both work outcomes and levels of psychological well-being than did time- and behavior-based conflict.

Keywords: Work Experiences, Well-Being, Work satisfaction and engagement, Physicians, Turkey

Work-family issues have received increasing attention by both organizations interested in effective human resource management and by researchers. Work-family issues, whether seen in terms of conflict, balance or synergy, have important consequences for individuals, families and organizations. Work-family conflict has been found to be associated with lower levels of work satisfaction, organizational commitment, absenteeism, and psychological well-being (Allen, Herst, Bruck \& Sutton, 2000; Byron, 2005; Kossek \& Ozek 1998; Parasuraman \& Greenhaus, 1997). Work-family conflict was also found to be associated with lower levels of family satisfaction as well (Eby, Casper, Lockwood, Bordeaux \& Brinley, 2005; Rice, Frone \& McFarlin, 1992). Finally, employee dissatisfaction and heightened turnover resulting from work-family issues also have implications for organizational performance (Goff, Mount \& Jamison, 1990; Jones, Burke \& Westman, 2005).

Research on the antecedents and consequences of work-family conflict have sometimes produced inconsistent results however, influenced in part by the use of different outcomes and different measures of work-family conflict.

Carlson, Kacmar and Williams (2000), based on previous theorizing and research findings, developed a measure of work-family conflict. Their measures examined both work-family and family-work relationships (bi-directional conflict) and different forms of conflict (time-strain- and behavior-based).

Time-based -the time devoted to one role makes it more difficult to participate successfully in the other role. 
Strain-based-strains in one role make it more difficult to participate or be successful in the other role.

Behavior-based -behaviors expected or required in one role are incompatible with behaviors required or expected in the other role

Thus there are six dimensions of work-family conflict: workfamily and family-work in each of the three forms. They found that these six measures were all positively and significantly correlated (average inter-correlation of .64). They also found that females scored significantly higher than males on four of the six measures. In addition, the strain-based measures were more strongly and consistently correlated with both potential antecedents and outcomes than were the time-based measures.

The present study replicates and extends findings from the original Carlson, Kacmar and Williams (2000) study. Their measures of work-family conflict were only used in this research since other research has shown that work-family conflict is generally more strongly and consistently related to work and well-being outcomes (Byron, 2005; Jones, Burke \&Westman, 2005). Their measures of work-family conflict were used in a large sample of employed men and women working in management and professional jobs in the manufacturing sector in Turkey. Turkey is a large developing country having a secular but almost exclusively Muslim population. In addition, the values of Turkey are different from those of Western countries (Hofstede, 1980), though these are slowly changing, and Turkey places a high value on the family (Aycan, 2004).In addition, human resource management practices in Turkey tend to be patriarchal (Aycan, 2001). Finally, the work ethic among employees in Turkey is different from that found in developed Western countries (Ali \& Al-Owaihan, 2008).

The initial Carlson, Kacmar and Williams (2000) study was also extended by including additional potential antecedents and consequences. The former included personal and demographic characteristics, indicators of job demands, and measures of personality associated with work investments; the latter included a wider array of work and well-being consequences.

Carlson (1999), using the same US sample as in her 2000 study, reported correlations between Type a behavior and negative affectivity, both personality factors, and the three forms of work-family conflict. As predicted negative affectivity was positively related to levels of each of the three forms of work-family conflict. Contrary to predictions, 
however, Type A behavior was negatively related to each of the three forms of work-family conflict. She suggests that Type As may be more adaptive, involved in a wider array of activities, be able to compartmentalize work and family, or be so involved in their work that they are oblivious to family matters. .

The following general hypotheses, building primarily on the Carlson et al. findings, were considered.

1. The measures of time-, strain, and behavior -based work-family conflict would be significantly and positively correlated.

2. The three measures of work-family conflict would have different predictors.

3. Personal demographic and work situation factors would be modest predictors of forms of WFC.

4. Stable individual difference personal characteristics associated with work investment (need for achievement, workaholic behaviors) would be strong predictors of forms of WFC

5. The three measures of work-family conflict would have different relationships with work and well-being outcomes. Strain-based conflict would have more relationships with work and well-being outcomes than would time-based conflict.

\section{Method}

\section{Procedure}

Data were collected from organizations in 16 Turkish cities (e.g., Denizli, Mersin, Nevsehir). Members of the research team contacted organizations in the manufacturing sector in these cities requesting their participation in the research. Cooperating organizations than provided a list of their managers and professionals. Approximately 1500 managers and professionals were contacted; 945 returned questionnaires to the research team of which 877 provided reasonably complete data, a 58\% response rate. Questionnaires were completed anonymously. Measures originally develop in English were translated into Turkish using the back translation method. 
Organizations fell into a variety of industries including agricultural machinery, textiles, health products, construction, food processing, furniture, metal, carpet production and electrical products. The respondents are best described as a large sample of Turkish managers and professionals in the manufacturing sector.

\section{Respondents}

Table 1 presents the demographic characteristics of the sample. Most respondents were male $(77 \%)$, married $(72 \%)$, were between 26 and 35 years of age (47\%), had children $(74 \%)$, had 2 children (44\%), were college/university graduates (63\%), held supervisory jobs (82\%), worked between 41-50 hours per week (49\%), earned between US $\$ 10,000$-US $\$ 14,000$ income $(24 \%)$, had 5 years or less of organizational tenure (45\%) and 5 years of less of job tenure $(62 \%)$, worked in organizations having 250 or fewer employees $(77 \%)$, and worked in production or accounting and finance $30 \%$ and $28 \%$. respectively). There was a tendency for a higher proportion of males to work in production and management and a lower percentage of males to work in marketing or accounting and finance.

\section{Measures}

Work-Family conflict

Three aspects of work-family conflict were assessed using scales developed by Carlson, Kacmar and Williams (2000). Each had three items and assessed time-, strain-, and behavior-based conflict. The respective reliabilities for these were $.85, .83$, and .75 . One item was "The stress from my job often makes me irritable when I get home."

Predictors of WFC

\section{Personal Demographic and work Situation Characteristics}

A number of personal demographics (e.g., age, gender, level of education, marital and parental status) and work situation characteristics (e.g., organizational level, job and organizational tenure) were measured by single items (see Table 1 ).

Job demands

Two job demands were included.

Work hours were assessed by a single item. Respondents indicated the number of hours they worked in a typical week. 
Work intensity was assessed by a 15 item scale $(a=.85)$. Some items were taken from Hewlett and Luce (2006) while others were developed by the researchers. Items included: "an unpredictable flow of work", "availability to clients 24/7", and a "large scope of responsibility that amounts to more than one job".

Personality Characteristics included.

Four stable individual difference personality characteristics were

Need for Achievement (NAch)

Need for Achievement (NAch) was measured by a five item scale $(a=.66)$ developed by Steers and Braunstein (1976). One item was "I try very hard to improve on my past performance at work."

\section{Workaholic Behaviors}

Two workaholic behavior scales developed by Mudrack (2007) were included. One, Non-required work, had 4 items $(a=.85)$. An item was "Thinking of ways to improve the quality fo work provided to customers and/or co-workers." The other, Control of others, also had 4 items $(a=.76)$. One item was "fixing problems created by other people".

A third workaholic component, Feeling driven to work because of inner pressures, developed by Spence and Robbins (1992) contained 7 items $(a=.71)$. One item was "I often feel that there is something inside me that drives me to work hard."

Work and Well-Being Outcomes

A wide range of outcome variables were included in this study covering both work and extra-work domains. These variables were consistent with those typically used in studies of work and well-being more generally (e.g., Barling, Kelloway \& Frone, 2005; Schabracq, Winnubst \& Cooper, 2003).

\section{Work Outcomes}

Four work outcomes were included.

Job satisfaction was measured by a seven item scale $(a=.81)$ developed by Kofodimos (1993). An item was "I feel challenged by my work.".

Career satisfaction was assessed by a five item scale $(a=.86)$ created by Greenhaus, Parasuraman and Wormley (1990). One item 
was "I feel satisfied with the progress I have made in my career to date."

Job stress was measured by a nine item scale $(a=.58)$ developed by Spence and Robbins (1992). One item was "sometimes I feel like my work is going to overwhelm me."

Intent to quit was measured by two items $(a=.66)$ used previously by Burke (1991). One item was "Are you currently looking for a different job in a different organization? (yes/no).

Psychological Well-Being

Three aspects of psychological well-being were considered. the Maslach

Exhaustion was measured by a nine item scale $(a=.86)$, part of Burnout Inventory, developed by Maslach, Jackson and Leiter (1996). An item was "I feel emotionally drained from my work."

Psychosomatic symptoms was measured by a nineteen item scale $(a=.88)$ developed by Quinn and Shepard (1974). Respondents indicated how frequently they had experienced each physical symptom (e.g., headaches, difficulty sleeping) in the past year.

Life satisfaction was assessed by a five item scale $(a=.84)$ created by Diener, Emmons, Larsen and Griffin (1985). A sample item was "I am satisfied with my life."

\section{Results}

\section{Descriptive Statistics}

The three measures of WFC had acceptable levels of internal consistency reliability and were significantly and positively correlated $(p<.001)$ : time- and strain-, .62; time- and behavior-, .33; and strainand behavior-.37; the average correlation being.44. These values were similar to those reported by Carlson, Kacmar and Williams (2000):.58, $.31, .54$, and an average inter-correlation of .48.

The mean values of the three WFC measures were: time-, 3.1; strain- 2.9, and behavior-, 3.1; the average being 3.1. Carlson, et al (2000) reported mean values of 2.8, 2.6, 2.5, and 2.6, respectively. Respondents in the Turkish sample reported significantly higher levels of WFC than did respondents in the Carlson, et. al (2000) American study. Carlson and her colleagues reported significant gender differences; females reporting significantly higher levels of strain-based WFC than did males. Males tended to report more WFC on all three 
measures in the present Turkish study but none of these differences were statistically significant.

\section{Analysis Strategy}

In order to better understand the sources of the three forms of WFC, correlations were computed between the experience of each form and personal and work situation characteristics, job demands, and the personality factors. Then to examine the potential consequences of the forms of WFC, hierarchical regression analyses were undertaken in which the measurers of the four work outcomes and the three indicators of psychological well-being were separately regressed on three blocks of predictors entered in a specified order. The first block of predictors $(\mathrm{N}=5)$ consisted of personal demographics (e.g., age, gender, level of education). The second block of predictors $(\mathrm{N}=6)$ included work situation characteristics (e.g., organizational level, job and organizational tenure). The third and final block of predictors $(\mathrm{N}=3)$ were the forms of WFC. When a block of predictors accounted for a significant amount or increment in explained variance on a given criterion variable $(p<.05)$, individual items or measures within such blocks having significant and independent relationships with these criterion variables were then identified $(p<.05)$. These analyses control for the relationships of both personal demographics and work situation characteristics before examining the relationship of forms of WFC and the work and well-being variables of interest.

Predictors of Forms of WFC

\section{Personal and work situation characteristics}

Correlations were computed between 12 personal demographic characteristics and the three forms of WFC:-time-, strain-, and behavior-based. Only 7 of the resulting 36 correlations (19\%) were significantly different from zero $(p<.05)$. None exceeded .10 . Older respondents indicated less strain-based WFC; respondents having more children reported more behavior-based WFC; respondents earning higher incomes indicated less strain-based WEFC but more behaviorbased WFC; those at higher organizational levels indicated less strainbased conflict, respondents having longer organizational tenure also indicated less time-based WFC and less strain-based WFCV, and respondents having longer job tenure also indicated less strain-based WFC. These data indicate weak and inconsistent relationships between personal demographic and work situation characteristics and levels of WFC, and provide support for the first hypothesis. 


\section{Job demands}

The top half of Table 2 shows the correlations of two job demands (hours worked, work intensity) and the three forms of WFC. Five of the six correlations were significantly different from zero $(p<.05)$, and all were positive, as predicted in hypothesis 2 . Respondents working more hours per week indicated higher levels of time- and strain-based WFC: respondents reporting higher work intensity reported higher levels of time-, strain-, and behavior-based WFC.

\section{Personality Characteristics}

The bottom half of Table 2 shows the correlations between four personality characteristics (NAch, three workaholic components) and the three forms of WFC. Five of the resulting 12 correlations (42\%) were significantly different from zero $(p<.05)$ but only three of the five positive in sign as predicted in hypothesis 3. Respondents scoring higher on NAch indicated less strain-based WFC; respondents scoring higher on Non-required work also indicated lower levels of strain-based WFC; but respondents scoring higher on Feeling driven to work because of inner pressures also reported higher levels of time-l strain- and behavior-based WFC. These findings provide partial support for the third hypothesis. They also suggest a potentially important role for emotions in the work-family conflict relationship in light of the link between the addictive elements in feeling driven to work (see Burke, 2007) and all three measures of WFC.

\section{Consequences of Work-Family Conflict \\ WFC and Work outcomes}

Table 3 presents the results of hierarchical regression analyses in which four work outcomes were separately regressed on the three blocks of predictors. The following comments are offered $n$ summary. First, all three blocks of predictors accounted for a significant amount or increment in explained variance on job satisfaction. Respondents with children, respondents at higher organizational levels, and respondents indicating lower levels of strain-based WFC reported more 
job satisfaction (Bs=-.12, .23 and -.14, respectively). Second, all three blocks of predictors accounted for a significant amount or increment in explained variance on career satisfaction. Respondents at higher organizational levels, respondents having longer organizational tenure, and those indicating lower levels of strain-based WFC indicated higher levels of career satisfaction (Bs=.21, .13 and -.10 , respectively). Third, two of the three blocks of predictors accounted for significant increments in explained variance on job stress (not personal demographics). Respondents with longer organizational tenure, respondents at lower organizational levels, respondents indicating higher levels of strain-based WFC and those indicating higher levels of time-based WFC indicated higher levels of job stress (Bs=.16, -.10, .35, and .13, respectively). Finally, all three blocks of predictors accounted for a significant amount or increment in explained variance on int net to quit. Single respondents, respondents having shorter organizational tenure, those having longer job tenure, and those reporting higher levels of strain-based WFC were more likely to intend to quit (Bs=-.14, $.15, .14$ and .18 , respectively). These results provide support for the fourth hypothesis.

\section{WFC and Psychological Well-Being}

Table 4 shows the results of hierarchical regression analyses in which three indicators of psychological well-being were regressed on the three blocks of predictors. The following comments are offered in summary. First, all three blocks of predictors accounted for a significant amount or increment in explained variance on exhaustion. Respondents having more education, respondents at lower organizational levels and respondents reporting more strain-based WFC also indicated higher levels of exhaustion (Bs=.11, -.12, and .39, respectively) Second, al three blocks of predictors also accounted for a significant amount or increment $\mathrm{n}$ explained variance on psychosomatic symptoms. Women, respondents at lower organizational levels and respondents indicating higher levels of strain-based WFC also reported more psychosomatic symptoms (Bs=-.10-, -.10 , and .16, respectively). Finally, al three blocks of predictors accounted for a significant amount or increment in explained variance on life satisfaction. Respondents at higher organizational levels, those having longer organizational tenure and those indicating less strain-based WFC also reported greater live 
satisfaction (Bs=.26, .16 and.- .13 , respectively). These findings provide support for the fifth hypothesis.

Two other observations are worth noting. First, strain-based WFC emerged as the strongest and most consistent predictor of both work outcomes and indicators of well-being (see Table 3 and 4). Second, the WFC measures accounted for a larger amount of explained variance in about half thee analyses reported in Table 3 and 4.

\section{Discussion}

This study replicated and extended the development of a measure of work-family conflict and its initial validation carried out in the US by Carlson, Kacmar and Williams (2000). Data were collected from a large sample of women and men employed in the manufacturing sector in Turkey using anonymously completed questionnaires. In addition, more potential predictors and consequences of work-family conflict were included in the Turkish study.

Our findings replicated the earlier US -based study in several areas. First, the three work-family conflict measures (time-, strain, and behavior-based conflict) had acceptable levels of internal consistency reliability and were inter-correlated to the same extent in the Turkish sample as in the US sample. In addition, work-family conflict was related to outcomes in generally the same way; that is, higher levels of work-family conflict tended to be associated with less favorable work and well-being outcomes,. Interestingly, strain-based work -family conflict was more strongly related to these outcomes than were either time- or behavior-based conflict. Finally, our findings and those of Carlson (1999), showed that stable individual difference personality factors added additional understanding of forms of work-family conflict, and, somewhat surprising $=\mathrm{y}$, more work-oriented respondents (higher Type As, great feelings of being driven to work because of inner pressures, more NAch) indicated lower levels of work-family conflict. These counter-intuitive results obviously call for more research attention.

The present study also extended the Carlson, et. al (2007) research in several important ways. First, our understanding of the predictors of these three forms of work-family conflict has been increased(see Table 2); personal and work situation characteristics had weak and inconsistent relationships with the three forms of work-family 
conflict, job demands (work hours and work intensity) had strong and consistent relationships with the three forms of work-family conflict, and individual difference personality factors related to greater work commitment were also strongly and consistently related to the three forms of work-family conflict. These findings reflect the fact that work experiences are more likely to affect family well-being than family experiences affect work well-being (Byron, 2005).

Our understanding of potential consequences of these three forms of work-family conflict has also increased. Work-family conflict predicted a range of work and well-being outcomes (see Table 3 and 4). Furthermore, strain-based work-family conflict was found to have the strongest and most consistent relationships with these outcomes. Carlson, Kacmar and Williams (2000) also found that strain-based conflict had the strongest relationships with the outcomes used in their US study.

These results fit with the recent emphasis being devoted to the role of emotions both positive and negative- in the workplace (Ashkanasay, Hartel \& Zerbe, 2000; Cameron, Dutton \& Quinn, 2003; Fineman, 1996). Emotions have traditionally been ignored in organizational behavior scholarship (Fineman, 1996). In addition, recent studies have documented the transmission of both positive and negative emotions from work to family, and among family members (Bakker, Demerouti \& Dollard, 2008; Westman, 2001, 2005).

Practical implications

Some preliminary practical implications can be drawn from these findings. First, individuals and organizations would profit by offering personal coaching and training programs that address the consequences of excessive work involvement for family and personal well-being. Second, organizations might consider ways of reducing levels of work intensity. Munck (2001) outlines what the Marriot hotel chain did to reduce both work hours and work intensity. of supervisory and managerial staff. Third, individuals and organizations might consider ways that individuals following a particularly demanding work day can recover while at home (see Sonnentag \& Fritz, 2007).

\section{Limitations of the research}

This research, like most others, has some limitations. First, all data were collected using self-report questionnaires raising the small 
possibility of responses being affected by use of a common method. Second the data were collected at one point in time making it difficulty to establish causal relationships. Third, a few of the measures had levels of internal consistency reliability below the generally accepted level of .70. Fourth, although the sample was large, it was not likely a representative sample of Turkish managers and professionals in the manufacturing sector. Fifth, the extent $o$ which these findings would generalize to respondents working in other industrial sectors or respondents in other countries is yet to be determined.

Future research directions

First, the role played by stable personality characteristics as antecedents of WFC needs more attention. Second, the use of diary studies needs to be integrated with the use of broader surveys in the same investigation. Third, more use of longitudinal studies needs to be undertaken. For example, Dikkers, Geurts, Kompier, Taris, Houtma and van den Heuvel (2007) found, in a longitudinal study, that workload caused work-home interference and that work-home interference also caused future workload. 


\section{References}

Ali, A. J., \& Al-Owaihan, A. (2008) Islamic work ethic: A critical review. Cross cultural Management, 15, 5-19.

Allen, T. D.., Herst, D. E. L., Bruck, C. S., \& Sutton, M. (2000) Consequences associated with work to family conflict: $A$ review and agenda for future research. Journal of Occupational Health Psychology, 5, 278-308.

Ashkanasay, N. M., Hartel, C. E. J., \& Zerbe, W. J. (2000) Emotions in the workplace: Research, theory, and practice. Westport, CT: Quorum Books.

Aycan, Z. (2004) Key success factors for women in management in Turkey. Applied Psychology: An International Review, 53, 453-277.

Aycan, Z. (2001) Human resource management in Turkey: Current issues and future challenges. International Journal of Manpower, 22, 252-260.

Bakker, A. B., Demerouti, E., \& Dollard, M. F. (2008) How job demands affect partner's experience of exhaustion: Integrating work-family conflict and crossover theory. Journal of Applied Psychology, 93, 901-911.

Barling, J., Keloway, E. K., \& Frone, M. R. (2005) Handbook of work stress. Thousand Oaks, CA: Sage :Publications.

Burke, R. J. (2007) Research companion to working hours and work addiction. Chichester, UK: Edward Elgar.

Burke, R. J., (1991) Early work and career experiences of female and male managers and professionals: Reasons for optimism? Canadian Journal of Administrative Sciences, 8, 224-230.

Byron, $K$. (2005) A meta-analytic review of work-family conflict and its antecedents. Journal of Vocational Behavior, 67, 169-198.

Cameron, K. S., Dutton, J. E., \& Quinn, R. E. (2003) Positive organizational scholarship: Foundations of a new discipline. San Francisco: BerrettKoehler.

Carlson, D. S. (1999) Personality and role variables as predictors of three forms of work-family conflict. Journal of /vocational Behavior, 55, 236-253.

Carlson, D., Kacmar, J., \& Williams, L. (2000) Construction and initial validation of a multi-dimensional measure of work-family conflict. Journal of Vocational Behavior, 56, 249-278.

Diener, E., Emmons, R,. A., Larsen, R. J., \& Griffin, S. (1985) The Satisfaction with Life Scale. Journal of Personality Assessment, 49, 71-75. 
Dickers, J. S. E., Geurts, S. A. E., Kompier, M. A. J., Taris, T. W., Houtman, I. L. D., \& van den Heuvel, $F$ (2007) Does workload cause work-home inte4rerence or is the other way around? Stress and Health, 1232, 303314.

Eby, L. T., Casper, W., Lockwood, A., Bordeaux, C., \& Brinley, A. (2005) Work and family research in IIO/OB: Content analysis and review of the literature (1980-2002). Journal of Vocational Behavior, 66, 124-197.

Fineman, S. (1996) Emotions in organizations. $2^{\text {nd }}$ edition. Thousand Oaks, CA: Sage Publications.

Greenhaus, J. H., Parasuraman, S,., \& Wormley, W. (1990) Organizational experiences and career success of black and white managers. Academy of Management Journal, 33, 64-86.

Hewlett, S. A., \& Luce, C. B. (2006) Extreme jobs: The dangerous allure of the 70-hour work week. Harvard Business Review, December, 49-59.

Hofstede, G. (1980) Culture's consequences: International differences in workrelated values. Beverly Hills, CA: Sage Publications.

Jones, F., Burke, R. J., \& Westman, M. (2005) Work-life balance: A psychological perspective. East Sussex, ,UK: Psychology Press

Kofodimos, J. (1993) Balancing act. San Francisco: Jossey-Bass.

Kossek, E. E., \& Ozeki, C. (1998) Work-family conflict, policies, and the job-life satisfaction relationship: a review and directions for organizational behavior-human resources research. Journal of Applied Psychology, 83, 139-149.

Maslach, C., Jackson, S. E., \& Leiter, M. P. (1996). Maslach Burnout Inventory, $3^{\text {rd }}$ ed. Palo Alto, CA: Consulting Psychologists Press.

McClelland, D. C. (195) Human motivation. Glenview, Ill.: Scott, Forsman.

Mudrack, P. E. (2007) Understanding workaholism: The case for behavioral tendencies. In R. J. Burke (ed,.) Research companion to working time and work addiction. Chichester, UK: Edward Elgar. pp. 108-128.

Munck, B. (2001) Changing a culture of face time .Harvard Business Review, November, 3-8.

Parasuraman, S., \& Greenhaus, J. H. (1997) Integrating work and family: Challenges and choices for a changing world. Westport, CT: Quorum Books.

Quinn, R. P., \& Shepard, L. J., (1974) The 1972-73 Quality of Employment Survey. Ann Arbor, MI: Institute for Social Research, University of Michigan. 
Rice, R. W., Frone, M. R., \& McFarlin, D. B. (1992) Work-nonwork conflict and the perceived quality of life. Journal of Organizational Behavior, 13, 155168.

Schabracq, M. J., Winnubst, J. A. M., \& Cooper, C. L (2003) The handbook of work and health psychology. West Sussex, UK: John Wiley.

Sonnentag, S., \& Fritz, C. (2007) The Recovery Experience Questionnaire: Development and validation of a measure for assessing recuperation and unwinding from work. Journal of Occupational Health Psychology. 12, 204-221.

Spence, J. T., \& Robbins, A. S. (1992) Workaholism: Definition, measurement, and preliminary results. Journal of Personality Assessment. 58, 160178.

Steers, R. M,., \& Braunstein, D. N. (1976) Manifest Needs Questionnaire. In J. Cook, et. al. (eds.) Experience of work: A compendium and review of 249 measures and their use. New York: Academic Press. pp. 159-160.

Westman, M. (2005) Crossover of stress and strain in the work-family context. In F. Jones, R. J. Burke \& M. Westman (eds.) Work-life balance: $A$ psychological perspective. East Sussex, UK: Psychology Press. pp. 163184.

Westman, M., (2001) Stress and strain crossover. Human Relations, 54, 717753. 